\title{
Effect of Vermicompost on the Physicochemical Properties of Coastal
}

\section{Saline Soil}

\author{
Xiao Deng ${ }^{1,2, a}$, Xiang Meng ${ }^{3, b}$, Yi Li $^{1, \mathrm{c}}$, Chun-Yuan $\mathrm{Wu}^{1,2, \mathrm{~d}^{*}}$, Qin-Fen $\mathrm{Li}^{1,2, \mathrm{e}^{*}}$ \\ ${ }^{1}$ Environment and Plant Protection Institute, CATAS, Haikou, 571101, China \\ ${ }^{2}$ Experiment Station of Agricultural Environment Scientific Observation in Danzhou, Ministry of \\ Agriculture, P. R. China. Danzhou, 571737, China \\ ${ }^{3}$ Nanjing Agricultural University, Nanjing, 210095, China \\ adx0928@foxmail.com, b2016816154@njnu.edu.cn, cwish0310@163.com, \\ dwuchunyuan1981@126.com, eqinfenli2005@163.com, * Corresponding author
}

Keywords: Vermicompost, Coastal saline soil, Soil physicochemical properties

Abstract. Using pot experiment to study the effect of vermicopost on the physicochemical properties of coastal saline soil in water spinach plantation under conditions without chemical fertilizer utilization. Six treatments were designed by mixing vermicompost and saline soil in different volume ratios of $0: 20,2: 20,3: 20,4: 20,5: 20$ and 6:20. The results showed that adding vermicompost could obviously improve the $\mathrm{pH}$ value of coastal saline soil. The concentrations of organic matter, alkali-hydrolyzable $\mathrm{N}$, available $\mathrm{P}$ and available $\mathrm{K}$ of saline soil were all significantly higher than those of control treatment. The concentration of available $\mathrm{P}$ was increased $4.7 \sim 12.5$ times higher than that of control treatment. The concentrations of available K, alkali-hydrolyzable $\mathrm{N}$ and organic matter were increased $87.9 \% \sim 297.8 \%, 10.0 \% \sim 41.4 \%$ and $9.0 \% \sim 33.8 \%$, respectively. It was proved that the vermicompost can improve the physicochemical properties of coastal saline soil and achieve the purpose of soil improvement.

\section{Introduction}

The saline soil was widely distributed and its area is very large in China, especially in the coastal areas[1]. High soil salinity is a key factor of restricting land reclamation in coastal areas [2]. At present, it is generally believed that the biological measures are the most effective ways to improve saline soil in all kinds of technical measures. Applying organic fertilizer can change soil physical properties, improve soil aggregates and increase crop yield in the process of improvement on saline soil. The application of organic fertilizer can also increase the activity and quantity of soil microbial, promote the migration and transformation of salts in the soil and reduce salt concentration [3]. Vermicopost not only has good agglomerate structure, but also contains rich microorganisms and biological active substances, etc. Vermicopost can also increase the content of soil humus after plowing soil. Therefore, the function of vermicompost is better than that of general organic fertilizers on soil improvement [4,5]. The purpose of this study was to provide theoretical support for improving soil quality and promoting the sustainable utilization of soil by investigating the direct effects of vermicompost on physicochemical properties in coastal saline soil. 


\section{Materials and methods}

The tested soils were taken in coastal saline land of LuoDou farm (N 1959'28.4", E 110³7'2.3") of WenChang City in Hainan Province. And the concentration of soil chlorine ion was $2816 \mathrm{mg} \mathrm{kg}^{-1}$. Soil samples were taken from 0 20 cm tillage layer soil by applying five point sampling method. Samples were stored in a plastic bag and taken to the laboratory on the same day, the plant roots and stones were removed, and samples were passed through a $2 \mathrm{~mm}$ sieve after air drying. The tested vermicopost was from Danzhou agricultural production base of Hainan University. The tested plant was water spinach. The pot experiment was conducted in the greenhouse of Danzhou experimental base of Chinese Academy of Tropical Agricultural Sciences from August to September in 2016. Six treatments were designed by mixing vermicompost and coastal saline soil in different volume ratios of $0: 20,2: 20,3: 20,4: 20,5: 20$ and 6:20. Each treatment was repeated 3 times. The cultivation conditions and management methods of each pot was the same. All vermicompost and air drying soil were directly mixed for planting water spinach under conditions without chemical fertilizer utilization, and watered one time a day. Seven plants with the same growth status were remained to observe in each pot after seeds sprouting. The potted soil samples were collected after the harvest of water spinach, and passed through a $1 \mathrm{~mm}$ sieve after air drying to analyze the $\mathrm{pH}$ value, the concentrations of organic matter, alkali-hydrolyzable $\mathrm{N}$, available $\mathrm{P}$ and available $\mathrm{K}$ of soil. All soil physicochemical indexes were determined by reference to the agricultural industry standards. Descriptive statistics for estimation of means and standard deviations of samples were conducted using Excel 2010. Significant differences were analyzed by Duncan's method.

\section{Results and Discussion}

Fig.1 showed that the $\mathrm{pH}$ value of coastal saline soil was obviously improved after adding vermicompost under conditions without chemical fertilizer utilization. The $\mathrm{pH}$ value was 6.41 in coastal saline soil without adding vermicompost, belonging to acid soil. However, the $\mathrm{pH}$ values were $6.98 \sim 7.27$ in the treatments with adding vermicompost ratios of 2:20 $\sim 6: 20$, belonging to neutral soil. the $\mathrm{pH}$ value of coastal saline soil were increased $8.9 \% \sim 13.4 \%$ after adding vermicompost. And the soil $\mathrm{pH}$ value was increased with increasing of adding ratio of vermicompost in the treatments with volume ratios of 2:20 5:20, while slightly decreased in the treatment with adding vermicompost ratio of 6:20. The promoting effect of different treatments on the $\mathrm{pH}$ value of coastal saline soil was 5:20 > 6:20> 4:20>3:20>2:20. The results also showed that the $\mathrm{pH}$ value of five treatments with volume ratios of 2:20 6:20 were significantly higher than that of control treatment $(\mathrm{P}<0.05)$.

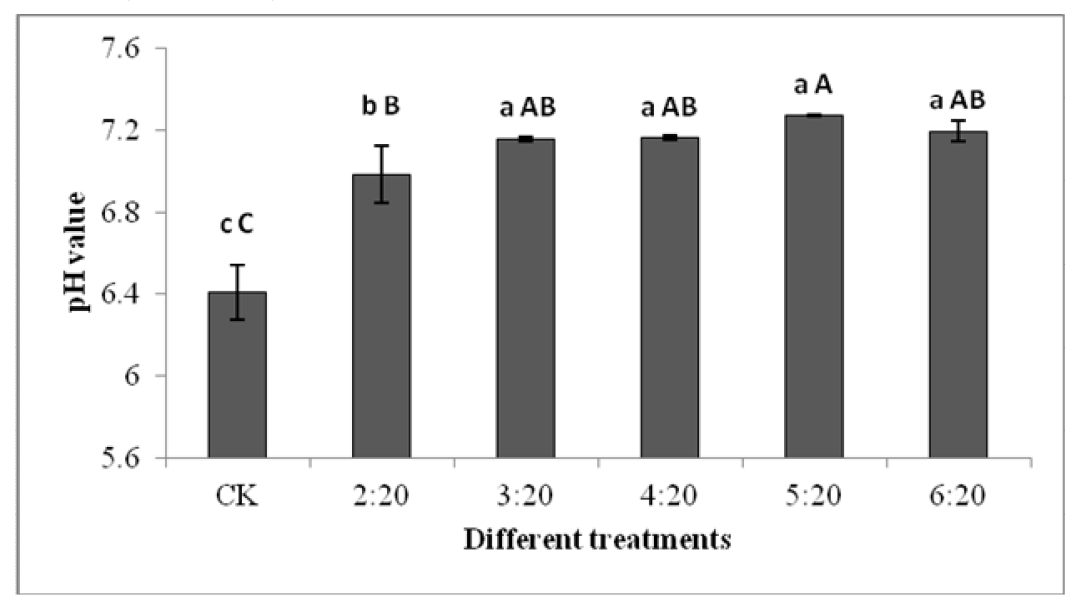

Fig. 1 Effect of vermicompost on the $\mathrm{pH}$ value in coastal saline soil 
The soil fertility can be reflected by the concentration of soil organic matter[6]. It also has an important influence on the composition and properties of soil salt and the improvement of soil salinization [7]. Fig. 2 showed that the concentrations of organic matter were increased $9.0 \%$ $33.8 \%$ after adding vermicompost in coastal saline soil under conditions without chemical fertilizer utilization. And the concentration of soil organic matter was increased with increasing of adding ratio of vermicompost in the treatments with volume ratios of 2:20 5:20, while slightly decreased in the treatment with adding vermicompost ratio of $6: 20$. The promoting effect of different treatments on organic matter of coastal saline soil was 5:20>6:20>4:20>3:20>2:20. The results also showed that the organic matter concentrations of four treatments with volume ratios of 3:20 6:20 were significantly higher than that of control treatment $(\mathrm{P}<0.01)$.

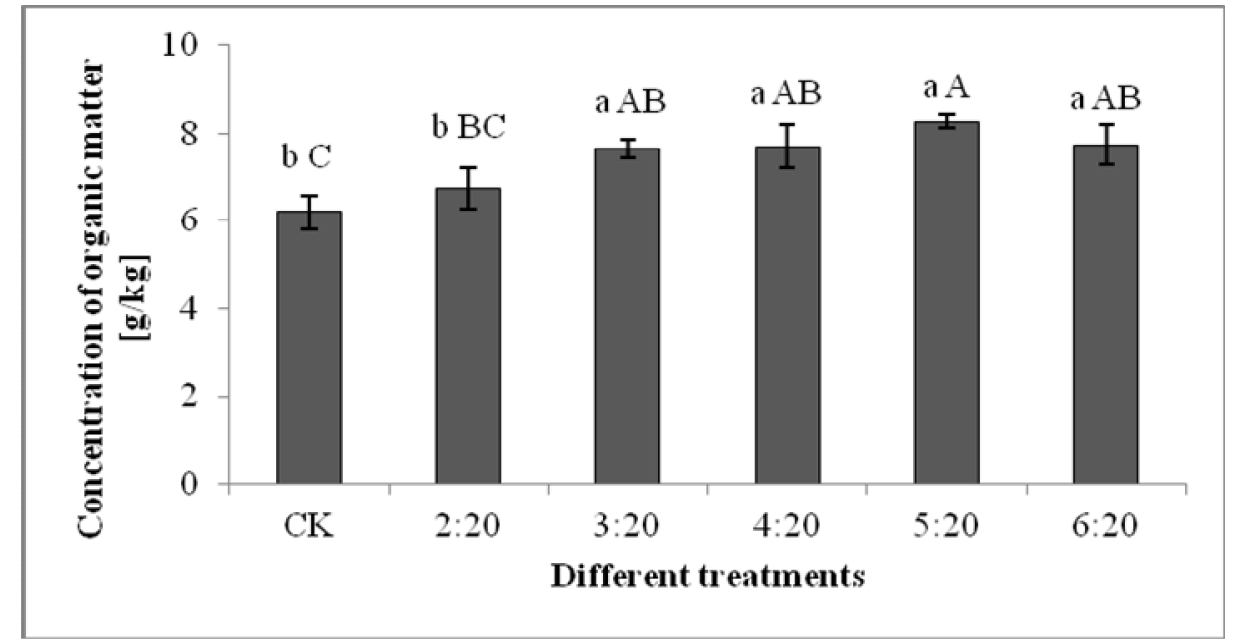

Fig. 2 Effect of vermicompost on the concentration of organic matter in coastal saline soil

Soil nitrogen is one of the most important nutrient elements on the growth and development of plants. Fig.3 showed that the concentrations of alkali-hydrolyzable N were increased $10.0 \%$ $41.4 \%$ after adding vermicompost in coastal saline soil under conditions without chemical fertilizer utilization. And the concentration of alkali-hydrolyzable $\mathrm{N}$ was increased with increasing of adding ratio of vermicompost in the treatments with volume ratios of 2:20 5:20, while slightly decreased in the treatment with adding vermicompost ratio of 6:20. The promoting effect of different treatments on the concentration of alkali-hydrolyzable $\mathrm{N}$ in coastal saline soil was 5:20>6:20 > 4:20 $>3: 20>2: 20$. The results also showed that the concentrations of alkali-hydrolyzable $\mathrm{N}$ in four treatments with volume ratios of 3:20 6:20 were significantly higher than that of control treatment $(\mathrm{P}<0.01)$.

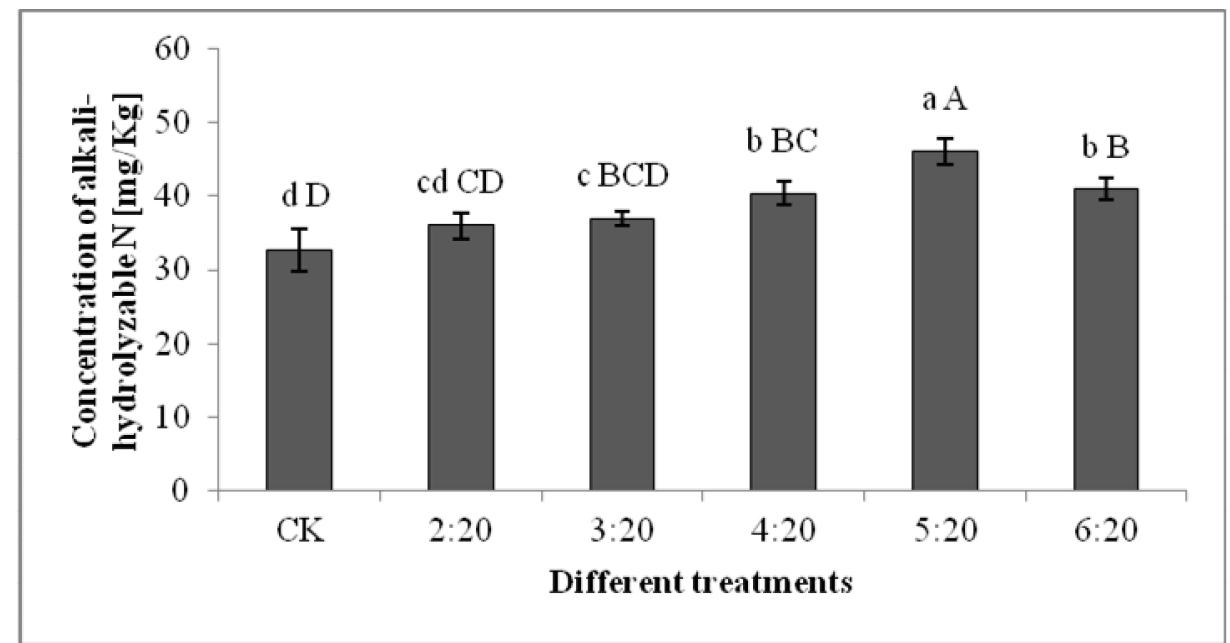

Fig. 3 Effect of vermicompost on the concentration of alkali-hydrolyzable $\mathrm{N}$ in coastal saline soil 
The influence of the concentration of available $\mathrm{P}$ on the growth and development of plants is very great. Fig. 4 showed that the concentrations of available $\mathrm{P}$ were increased $4.7 \sim 12.5$ times after adding vermicompost in coastal saline soil under conditions without chemical fertilizer utilization. And the concentration of available $\mathrm{P}$ was increased with increasing of adding ratio of vermicompost in the treatments with volume ratios of 2:20 5:20, while slightly decreased in the treatment with adding vermicompost ratio of 6:20. The promoting effect of different treatments on the concentration of available $P$ in coastal saline soil was 5:20>6:20>4:20 > 3:20 > 2:20. The results also showed that the concentrations of available $\mathrm{P}$ in five treatments with volume ratios of 2:20 6:20 were significantly higher than that of control treatment $(\mathrm{P}<0.01)$.

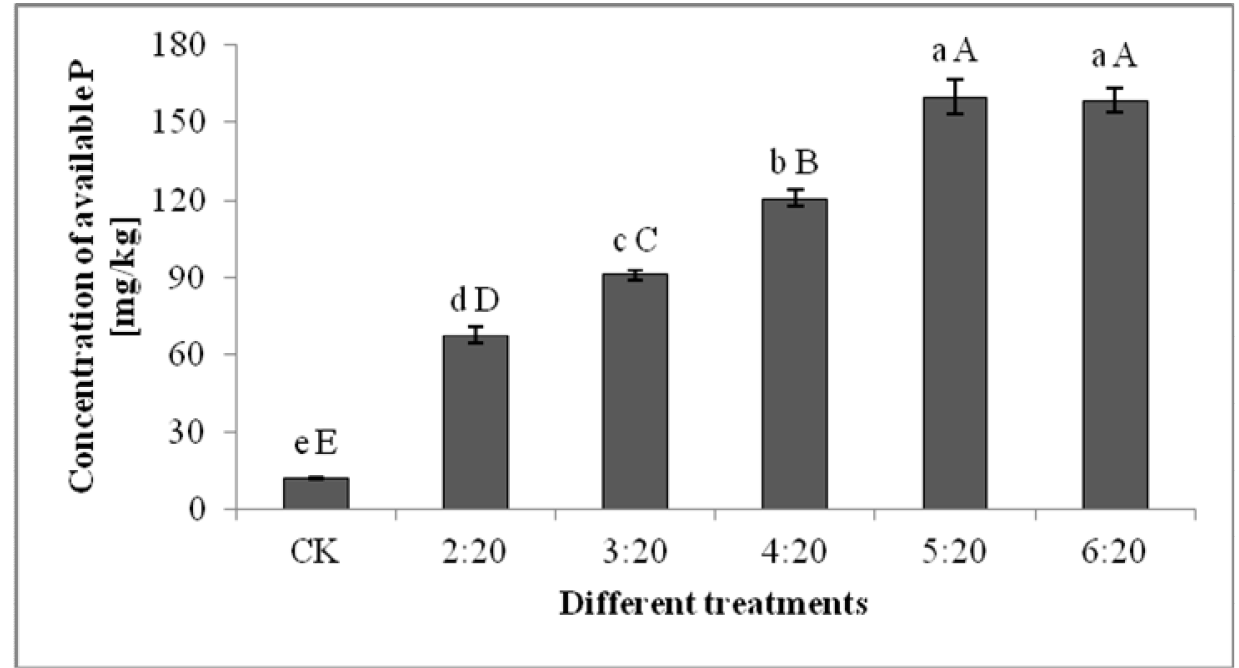

Fig. 4 Effect of vermicompost on the concentration of available $\mathrm{P}$ in coastal saline soil

Soil available $\mathrm{K}$ is an important indicator of the ability of soil supply potassium to crops. Fig.5 showed that the concentrations of available $\mathrm{K}$ were increased $87.9 \% \sim 297.8 \%$ after adding vermicompost in coastal saline soil under conditions without chemical fertilizer utilization. And the concentration of available $\mathrm{K}$ was increased with increasing of adding ratio of vermicompost in the treatments with volume ratios of 2:20 6:20. The promoting effect of different treatments on the concentration of available $K$ in coastal saline soil was $6: 20>5: 20>4: 20>3: 20>2: 20$. The results also showed that the concentrations of available $\mathrm{P}$ in five treatments with volume ratios of 2:20 6:20 were significantly higher than that of control treatment $(\mathrm{P}<0.01)$.

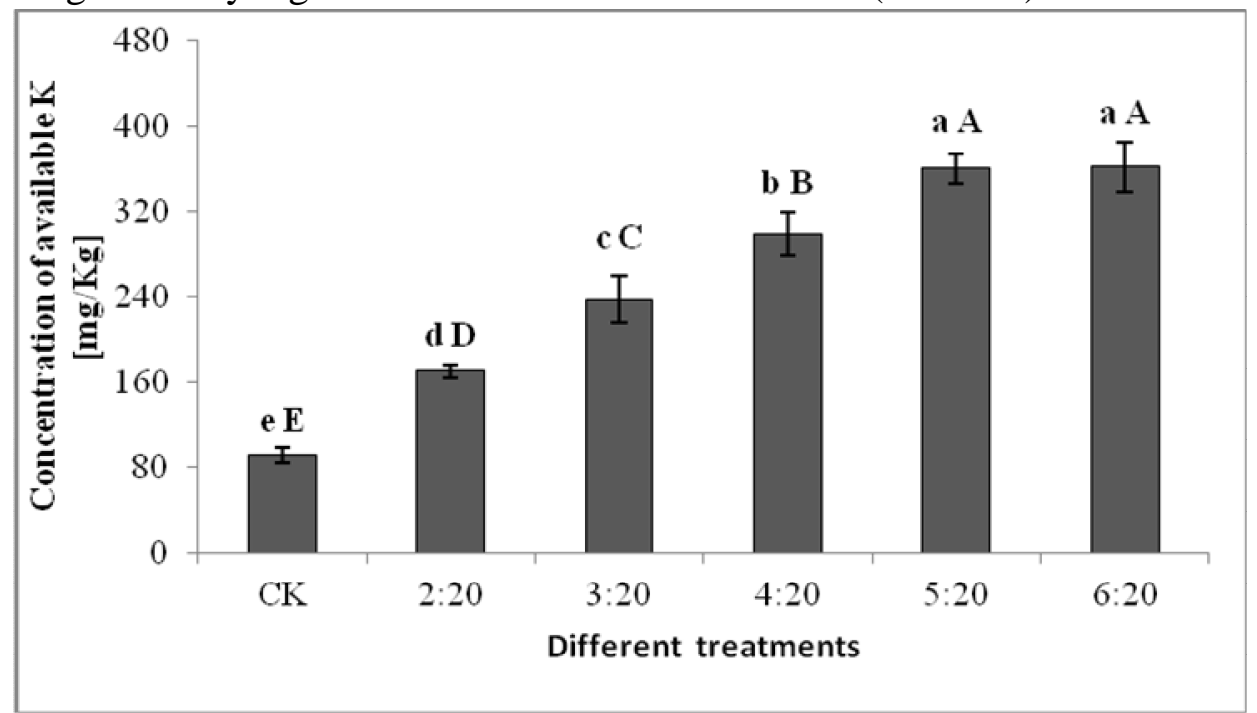

Fig.5 Effect of vermicompost on the concentration of available $\mathrm{K}$ in coastal saline soil 


\section{Conclusions}

In summary, the vermicompost can not only improve the $\mathrm{pH}$ value, but also significantly increase the concentrations of organic matter, alkali-hydrolyzable $\mathrm{N}$, available $\mathrm{P}$ and available $\mathrm{K}$ in coastal saline soil. This demonstrates that vermicompost can improve the physicochemical properties of the coastal saline soil and provide a favorable soil environment for crop growth. the concentrations of available $\mathrm{P}$ and available $\mathrm{K}$ were increased $4.7 \sim 12.5$ times and 87.91\% 297.8\% higher than those of control treatment, respectively. They are all belong to a very rich level in national soil nutrient classification criteria in China[8]. The concentrations of alkali-hydrolyzable $\mathrm{N}$ and organic matter were increased $9.97 \% \sim 41.41 \%$ and $9.04 \%$ 33.76\% higher than those of control treatment, respectively. However, they are still relatively low and belong to very low level in national soil nutrient classification criteria in China[8]. Therefore, we should pay attention to the application of $\mathrm{N}$ fertilizer and organic fertilizer in the process of applying the vermicompost to improve coastal saline soil.

\section{Acknowledgements}

This work was financially supported by the Key Research and Development Plan of Hainan Province (ZDYF2016149) and the Central Public-interest Scientific Institution Basal Research Fund (1630042017005).

\section{References}

[1] Y. C. Wang, D. X. Wang. Transactions of the CSAE, Vol. 28(2012), p. 151-158.

[2] Y. Y. Wu, R. C. Liu, Y. G. Zhao. Environ Geol, Vol.57 (2009), p. 1501-1508.

[3] L. Tao, G. X. Chu, T. Liu, C. Tang, J. H. Li, Y. C. Liang. Acta Ecologica Sinica, Vol. 34(2014), p.6137-6146.

[4] Z. N. Lv, Y. L. Ma. Chinese Agr. Sci. Bulletin, Vol. 21(2005), p. 236-240.

[5] L. L. Chen. Master thesis of Yangzhou University, (2011), p.25-30.

[6] T. J. Li, Y. S. Zheng, Y. Wang. Soil Geog., Published by the Beijing Higher Education Press. (1995), p.38-40.

[7] L. Y. Zhang, G. X. Zhao. Research Soil Water Conserv. Vol.13(2006), p. 32-34.

[8] National Agricultural Technology Extension Service Center. Investigation and Quality Evaluation of Cultivated Land. Published by China Agricultural Publishing press. (2005), p.86. 